\title{
Role of cervicovaginal $\beta$-hCG in prediction of preterm delivery: a prospective observational study
}

\author{
Ritika Gupta $^{1 *}$, Priyanka Mukherjee ${ }^{1}$, Harpreet Kaur ${ }^{1}$, Sahil Singhal ${ }^{2}$
}

\begin{abstract}
${ }^{1}$ Department of Obstetrics and Gynecology, Tata Main Hospital, Jamshedpur, Jharkhand, India
${ }^{2}$ Department of Medicine, ESIC Polyclinic, Alwar, Rajasthan, India
\end{abstract}

Received: 19 June 2020

Accepted: 31 July 2020

\author{
*Correspondence: \\ Dr. Ritika Gupta, \\ E-mail: ritikagupta128@gmail.com
}

Copyright: () the author(s), publisher and licensee Medip Academy. This is an open-access article distributed under the terms of the Creative Commons Attribution Non-Commercial License, which permits unrestricted non-commercial use, distribution, and reproduction in any medium, provided the original work is properly cited.

\begin{abstract}
Background: The World Health Organization (WHO) factsheet revealed that 15 million babies are born too early every year and almost 1 million children die each year due to complications of preterm birth. The objective of this study was to determine whether cervicovaginal $\beta$-hCG level can be used as predictor of preterm delivery in asymptomatic high-risk pregnant women at 24-34 weeks gestation age.

Methods: This was prospective observational study. Total 134 asymptomatic pregnant women were taken for study who had at least one risk factor for preterm delivery at 24-34 weeks gestation age. Cervicovaginal secretion was collected and $\beta$-hCG level was measured by chemiluminescent immunoassay.

Results: Out of 134 cases, $42.5 \%$ had preterm delivery and $57.5 \%$ had term delivery. Mean cervicovaginal $\beta$-hCG level $(\mathrm{mIU} / \mathrm{ml})$ in preterm delivery group was $39.38 \pm 19.66$ and term delivery group was $21.86 \pm 11.18$. Cervicovaginal $\beta$-hCG level was significantly higher in preterm group compare to term group demonstrating significant association of raised $\beta$-hCG with preterm group ( $\mathrm{p}$ value $<0.001$ ). ROC curve analysis was done to find out best cut off value of cervicovaginal $\beta$-hCG for prediction of preterm delivery and optimal cut off value was $36.45 \mathrm{mIU} / \mathrm{ml}$. The optimal cut off value for cervicovaginal $\beta$-hCG $(36.45 \mathrm{mIU} / \mathrm{ml})$ gave sensitivity $71.9 \%$, specificity $81.8 \%$, positive predictive value $74.5 \%$, negative predictive value $79.7 \%$ and diagnostic accuracy of $77.6 \%$ for prediction of preterm delivery. Conclusions: Cervicovaginal $\beta$-hCG can be used as sensitive and specific biomarker of prediction of preterm delivery in asymptomatic high-risk women.
\end{abstract}

Keywords: Biochemical predictor, Cervicovaginal $\beta$-hCG, Preterm delivery

\section{INTRODUCTION}

The World Health Organization (WHO) factsheet revealed that 15 million babies are born too early every year and almost 1 million children die each year due to complications of preterm birth. Preterm birth, i.e., birth before 37 weeks of gestation period, an important obstetric problem, is the major cause of neonatal mortality and morbidity across the globe. Preterm pregnancy accounts for about $10 \%$ of the total pregnancies. $^{1}$ Preterm delivery is one of the leading causes of perinatal morbidity and mortality. It accounts for nearly $70 \%$ of the neonatal deaths and $50 \%$ of longterm neurological sequelae. ${ }^{2}$

The risk of preterm birth is increased among women who have had a previous preterm birth. Previous preterm birth is the strongest risk factor for repeated preterm delivery and recurrences often occur at a similar gestational age, with around $70 \%$ delivering within 2 weeks of the gestational age of their first preterm delivery. ${ }^{3-8}$

Preterm delivery can be prevented and fetal lung maturation can be accelerated by early diagnosis of 
asymptomatic patients that are at a risk of preterm birth. If low risk of preterm birth is diagnosed, length of hospital stays and close follow-up visits can be decreased. Additionally, aggressive tocolysis therapy can be avoided. ${ }^{9}$

Identification and timely referral for specialized obstetrical evaluation and management of these high-risk women pre-conceptually or in early pregnancy, is important in reducing the morbidity, mortality, psychological trauma and expense associated with preterm birth. ${ }^{3}$

Research on many biomarkers in the maternal serum, amniotic fluid, and CVF are accomplished but not a single biomarker has evolved till date, which possesses sensitivity as well as reliability for the detection of spontaneous preterm birth. Study on a large sample size is needed for the confirmatory conclusion of use of biomarker in preterm delivery. A single biomarker or even in combination, if found for the prediction of Preterm labour, can decrease the hospital cost as well as restrict the treatment. The tocolytics or corticosteroids, which are generally used to prevent preterm birth, are found to cause severe side effects in both the mother and child, and its use can be minimized by predicting preterm delivery. Preterm delivery is a major and complex health care problem leading to neonatal mortality and thus, it needs to be focused on in more detail. ${ }^{10}$

Intensive research is underway to establish a reliable biomarker that can ascertain the risk of preterm delivery in pregnant women. Some of the biochemical markers proposed as predictor of preterm delivery are ${ }^{11}$

- $\quad$ Salivary estriol ${ }^{12,13}$

- Inflammatory cytokines (IL-6, IL-8, IL-10) $)^{14,15}$

- Fetal fibronectin ${ }^{16-18}$

- Alkaline phosphatase ${ }^{19,20}$

- Prolactin ${ }^{21,22}$

- Corticotropin-releasing hormone $\mathrm{e}^{23,24}$

- Cervicovaginal $\beta$-hCG.

Among those evaluated till date, fetal fibronectin in cervicovaginal fluid and cervical length has been most strongly and consistently associated with subsequent spontaneous preterm birth. ${ }^{16-18,25-28}$

Anai et al was the first to measure hCG levels in vaginal fluid. Their original study suggested that quantitative measurement of hCG from vaginal fluid may serve as a useful marker of premature rupture of fetal membranes secretions. ${ }^{9}$

Cervicovaginal presence of $\beta$-hCG in maternal serum and amniotic fluid are the result of diffusion throughout pregnancy. Source of elevated $\beta$-hCG in cervicovaginal secretions are maternal serum or amniotic fluid. Escape of $\beta$-hCG may be due to the inflammatory process that can precede the onset of preterm labour. ${ }^{29}$

Aim of present study was to find out an association between human $\beta$-hCG levels in cervicovaginal secretions and preterm labour, an appropriate cut-off value of human $\beta$-hCG levels in cervicovaginal secretions for prediction of preterm labour.

\section{METHODS}

This prospective observational study was conducted at Tata Main Hospital, Jamshedpur over a period of 1 year (1 November 2016 to 31 October 2017). Women (total no.160) were enrolled in my study according to inclusion criteria at gestational age 24-34 week having any one of them.

\section{Inclusion criteria}

Previous history of at least one preterm birth due to spontaneous preterm labour or premature rupture of membranes. One or more early pregnancy loss (defined as previous delivery of a conceptus showing no signs of life before 24 weeks gestation, excluding therapeutic abortions). Threatened miscarriage during present pregnancy were included in this study.

\section{Exclusion criteria}

Patient, who had confirmed rupture of fetal membranes, established preterm labour, multiple gestation, congenital malformation of uterus, anomalous fetus, current or planned cervical cerclage, antepartum hemorrhage, medical and Obstetric complications needing iatrogenic preterm delivery, abnormal pre pregnancy BMI (BMI>30 $\mathrm{kg} / \mathrm{m}^{2}$ ), medical disorder, were excluded from study.

Protocol was submitted to ethical institutional committee and permission was granted. An informed written consent for participation in the study was taken from patient. Routine antenatal care was given. Under all aseptic precaution, after explaining procedure and taking consent, cervicovaginal secretion sample was obtained during speculum examination. Patient was requested to lie down in semi flexed position after emptying bladder, sims speculum was introduced in to vagina. Any abnormal findings s/o any vaginal, cervical infection was noted down. A cotton tipped swab was placed first into the endocervical canal and then into the posterior fornix of vagina, each for 30 s. The swab was placed in a tube containing $1 \mathrm{ml}$ of saline solution and the tube was shaken for $1 \mathrm{~min}$ before the swab was disposed off. This sample was sent to laboratory immediately after collection. ${ }^{9}$ The assay procedure began with centrifugation of the solution at $3500 \times \mathrm{g}$ for $5 \mathrm{~min}$ to remove particulate matter. The remaining solution was quantitatively tested for the presence of $\beta$-hCG. Level of $\beta$-hCG was measured by chemiluminescent immunoassay using commercial kit $\left[\right.$ Access $2 \mathrm{TOTAL} \beta \mathrm{hCG}$ ( $5^{\text {th }}$ IS) 
standardized to the WHO $5^{\text {th }}$ International standard for chorionic gonadotropin] in this study institute laboratory. The level of $\beta-\mathrm{hCG}(\mathrm{mIU} / \mathrm{ml})$ then obtained was noted and patient was followed till delivery.

\section{Statistical analysis}

Statistical analysis was performed by the SPSS program for windows, version 17.0 (SPSS, Chicago, Illinois). Continuous variables were compared using the unpaired t-test, Mann-Whitney U-test. Categorical variables were analyzed using either the chi square test or Fisher's exact test. A receiver operating characteristics (ROC) analysis was done to determine optimal cut-off values for cervicovaginal $\beta$-hCG. The area under the curve and its standard deviation (AUC-SD), sensitivity, specificity, positive predictive value, negative predictive value was calculated to analyze the diagnostic accuracy of marker to predict preterm delivery. For all statistical tests, $\mathrm{p}$ value less than 0.05 was taken to indicate a significant difference.

\section{RESULTS}

Initially 160 pregnant women attending OPD and labour room, according to inclusion criteria were recruited for study at gestational age between 24 to 34 weeks. 26 women were either excluded or lost to follow-up. Thus, 134 women were available for final analysis.

Out of 134 cases, 57 cases $(42.5 \%)$ had preterm delivery $(<37$ weeks) and 77 cases $(57.5 \%)$ had term delivery $(\geq 37$ weeks). So, percentage of preterm delivery was $42.5 \%$ as shown in Table 2. Mean cervicovaginal $\beta$-hCG level $(\mathrm{mIU} / \mathrm{ml}$ ) in preterm group was $39.38 \pm 19.66$ and term group was $21.86 \pm 11.18$. Cervicovaginal $\beta$-hCG level was significantly higher in preterm group compare to term group. So, there was statistically significant association of raised $\beta$-hCG with preterm group ( $\mathrm{P}$ value- $<0.001$ ) as represented in Table 3 . ROC curve analysis was done to find out best cut-off value for $\beta$-hCG for prediction of preterm delivery in some way to minimize number of false positives and false negatives. Minimizing false positives and false negatives is same as maximizing sensitivity and specificity. The good first choice for test cut-off value is that value which corresponds to a point on ROC curve nearest to upper left corner of the ROC graph which was $36.45 \mathrm{mIU} / \mathrm{ml}$ in this study. So, best cut-off value for cervicovaginal $\beta$-hCG for prediction of preterm delivery was $36.45 \mathrm{mIU} / \mathrm{ml}$.

This study showed that among women, who had $\beta$-hCG level $\geq 36.45 \mathrm{mIU} / \mathrm{ml}, 74.5 \%$ had preterm delivery, while in women who had $\beta$ - hCG level $<36.45 \mathrm{mIU} / \mathrm{ml}$, only $20.3 \%$ had preterm delivery. So, there was a statistically significant association of raised cervicovaginal $\beta$-hCG level $\geq 36.45 \mathrm{mIU} / \mathrm{ml}$ for prediction of preterm delivery.

Table 1: Demonstrates demographic characteristics of study population.

\begin{tabular}{|c|c|}
\hline Demographic data & Value (\%) \\
\hline Age (years) $($ Mean \pm SD $)$ & $25.19 \pm 4.10$ \\
\hline BMI $\left(\mathrm{kg} / \mathrm{m}^{2}\right)$ & $25.4 \pm 5.1$ \\
\hline \multicolumn{2}{|l|}{ Parity } \\
\hline Primigravida & $44 / 134(32.8)$ \\
\hline Multigravida & $90 / 134(67.1)$ \\
\hline \multicolumn{2}{|l|}{ Socioeconomic class } \\
\hline Lower & 17.1 \\
\hline Middle & 67.1 \\
\hline Upper & 15.1 \\
\hline \multicolumn{2}{|l|}{ Risk factor } \\
\hline Previous preterm birth & 56 \\
\hline $\mathrm{H} / \mathrm{O}$ miscarriage & 29.8 \\
\hline Threated miscarriage & 28.8 \\
\hline
\end{tabular}

Table 2: Distribution of cases according to gestational age at delivery.

\begin{tabular}{|lll|}
\hline G.A. at delivery & Frequency $(\mathbf{n})$ & $\%$ \\
\hline$<37$ weeks & 57 & 42.5 \\
\hline$\geq \mathbf{3 7}$ weeks & 77 & 57.5 \\
\hline Total & 134 & 100.0 \\
\hline
\end{tabular}

Table 3: Mean cervicovaginal $\beta$-hCG level $(\mathrm{mIU} / \mathrm{ml})$ in preterm and term group.

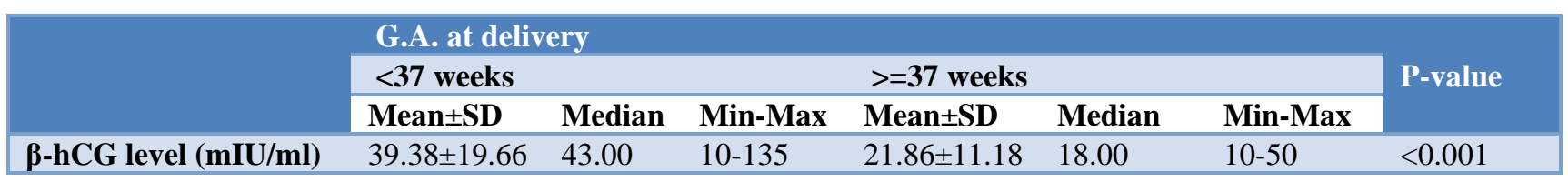

$\mathrm{P}$ value - Mean Whitney U test.

Table 4: Demonstrates receiver operator curve.

\begin{tabular}{|c|c|c|c|c|}
\hline \multirow{2}{*}{$\begin{array}{l}\text { Area under } \\
\text { curve }\end{array}$} & \multirow{2}{*}{ Std. error ${ }^{a}$} & \multirow{2}{*}{ Asymptotic Sig. } & \multicolumn{2}{|c|}{ Asymptotic $95 \%$ confidence interval } \\
\hline & & & Lower bound & Upper bound \\
\hline 0.781 & 0.043 & 0 & 0.697 & 0.866 \\
\hline
\end{tabular}


Table 5: Distribution of cases according to cervicovaginal $\beta$-hCG cut-off value and gestation age at delivery.

\begin{tabular}{|c|c|c|c|c|c|c|}
\hline \multirow{3}{*}{$\beta-h C G(m I U / m l)$} & \multirow{3}{*}{ Total cases } & \multicolumn{4}{|c|}{ G. A. at delivery } & \multirow{3}{*}{ P-value } \\
\hline & & \multicolumn{2}{|l|}{$<37$ weeks } & \multicolumn{2}{|l|}{$\geq 37$ weeks } & \\
\hline & & Frequency & $\%$ & Frequency & $\%$ & \\
\hline$<36.45$ & 79 & 16 & 20.3 & 63 & 79.7 & \\
\hline$\geq 36.45$ & 55 & 41 & 74.5 & 14 & 25.5 & $<0.001$ \\
\hline Total & 134 & 57 & 42.5 & 77 & 57.5 & \\
\hline
\end{tabular}

$\mathrm{P}$ value - chi square test.

Table 6: Sensitivity, specificity, positive predictive value, negative predictive value and diagnostic accuracy of cervicovaginal $\beta$-hCG for prediction of preterm delivery.

\begin{tabular}{|lllll|}
\hline Sensitivity (\%) & Specificity (\%) & PPV $(\%)$ & NPV (\%) & Accuracy $(\%)$ \\
\hline $\mathbf{7 1 . 9}$ & 81.8 & 74.5 & 79.7 & 77.6 \\
\hline
\end{tabular}

This study demonstrated that cervicovaginal $\beta$-hCG test had sensitivity $71.9 \%$, specificity $81.8 \%$, positive predictive value $74.5 \%$, negative predictive value $79.7 \%$ and diagnostic accuracy of $77.6 \%$ at cut-off value of $36.45 \mathrm{mIU} / \mathrm{ml}$ for prediction of preterm delivery.

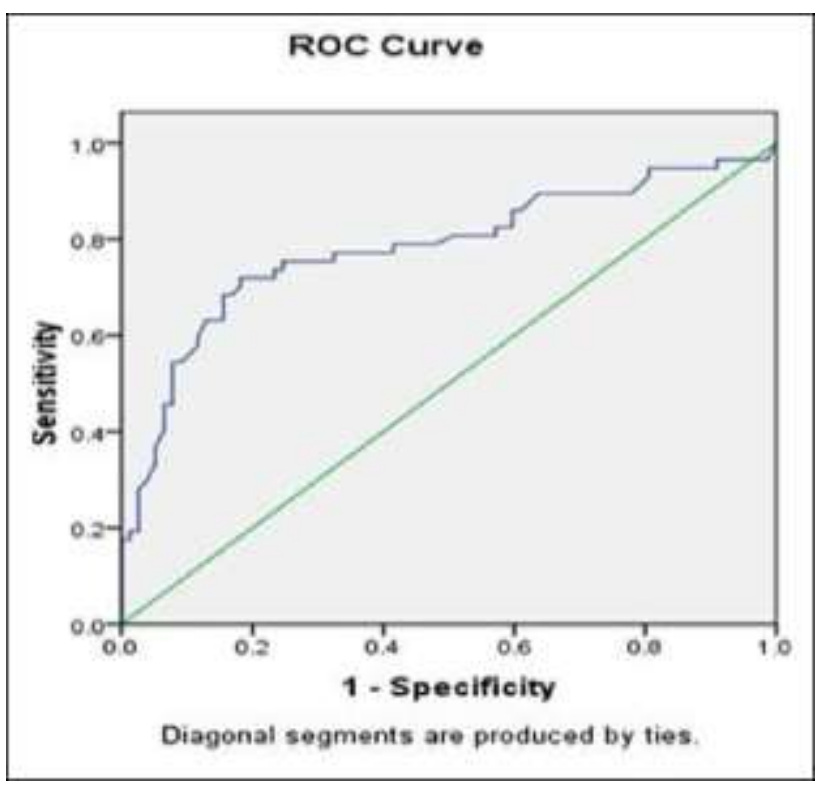

Figure 1: Demonstrates receiver operator curve.

\section{DISCUSSION}

Preterm birth (PTB) is an obstetric complication of complex etiology associated with significant neonatal mortality and morbidity worldwide. India alone accounts for $40 \%$ of the cases of low birth weight (LBW) in the developing world, and more than half of those in Asia. ${ }^{30}$ In order to reduce the incidence of preterm birth, intervention will be most useful if targeted towards a subgroup of women most likely to deliver preterm. So, identification of such subgroup of women by risk factor assessment and prediction of preterm birth constitutes important part of main strategy to reduce preterm birth.
In present study, authors have evaluated role of cervicovaginal $\beta$-hCG in prediction of preterm delivery in asymptomatic high-risk women at gestational age of 24 34 week. There was no statistically significant association of patient age and BMI with cervicovaginal $\beta$-hCG level.

Authors found significantly higher level of cervicovaginal $\beta$-hCG in the preterm delivery group as compared to term delivery group. There was significant association of raised $\beta$-hCG level with cut off value $\geq$ $36.45 \mathrm{mIU} / \mathrm{ml}$ in cervicovaginal secretion for prediction of preterm delivery in this study ( $p$ value $<0.001$ ). This test using $36.45 \mathrm{mIU} / \mathrm{ml}$ as cut off value, had sensitivity $71.9 \%$, specificity $81.8 \%$, positive predictive value (PPV) $74.5 \%$, negative predictive value (NPV) $79.7 \%$ and diagnostic accuracy $77.6 \%$ for prediction of preterm delivery in asymptomatic high-risk women.

Results of present study were comparable to other studies done by Bernstein et al who demonstrated that at cervico vaginal $\beta$-hCG cut off $>50 \mathrm{~m} \mathrm{IU} / \mathrm{ml}$ before 34 week gestation is having sensitivity, specificity, positive and negative predictive value of $50 \%, 87 \%, 33 \%$ and $93 \%$ respectively. ${ }^{31}$ Guvenal et al also found significant association of cervicovaginal $\beta$-hCG level in preterm labour group with cut off value of $27.1 \mathrm{mIU} / \mathrm{ml}$ having sensitivity, specificity, positive and negative predictive value of $87.5 \%, 65.4 \%, 28 \%$ and $97 \%$ respectively. ${ }^{21}$ Similar study by Gharshasbi et al found higher cut off value of $77.8 \mathrm{mIU} / \mathrm{ml}$ with sensitivity, specificity, positive and negative predictive value of $87.5 \%, 97 \%$, $88.5,98 \%$ respectively. ${ }^{32}$ Similarly, Abasalizadeh et al found lower sensitivity $(45.5 \%)$, higher specificity $(91.2 \%)$ and higher negative predictive value $(95.4 \%)$ at cut off level of $45 \mathrm{mIU} / \mathrm{ml}$ for cervicovaginal $\beta$-hCG for prediction of preterm delivery. ${ }^{33}$ Adhikari et al also concluded that cervicovaginal $\beta$-hCG may have a role in predicting preterm delivery both in symptomatic and asymptomatic women at high-risk for preterm delivery, but cut off value of $\beta$-hCG in their study was very low 14 $\mathrm{mIU} / \mathrm{ml}$ for predicting delivery $<34$ week with sensitivity, specificity, positive and negative predictive value of 
$83.3 \%, 85.5 \%, 33.3 \%$ and $98.3 \%$ respectively, 4.75 $\mathrm{mIU} / \mathrm{ml}$ for predicting delivery $<37$ week with sensitivity, specificity, positive and negative predictive value of $70 \%, 61.8 \%, 40 \%$ and $85 \%$ respectively as compared to present study. ${ }^{34}$

Present study had comparable sensitivity and negative predictive value to Erdalsak et al, Mishra et al. ${ }^{9,35}$ They found a cut off value of $13.5 \mathrm{mIU} / \mathrm{ml}$ for cervicovaginal $\beta$-hCG for prediction of preterm delivery with sensitivity $71.1 \%$, specificity $81.2 \%$.

This test had variable sensitivity, specificity, positive and negative predictive value in various studies. The variability in results across the studies may have arisen due to dissimilarities in case selection, as some studies selected both asymptomatic and symptomatic women, different timings of sample collection and diversities in the study population.

\section{CONCLUSION}

Authors conclude that because of ease of sample collection, low cost, wide availability, non-invasive nature, safety and simplicity of procedure, measurement of cervicovaginal $\beta$-hCG at 24-34 weeks gestation age with cut off value of $36.45 \mathrm{mIU} / \mathrm{ml}$ can be used as an excellent tool for early prediction of preterm birth in asymptomatic high-risk women.

\section{Recommendations}

Implementation of clinical risk factor assessment and use of biochemical marker for early prediction of preterm birth in high risk women might reduce perinatal mortality and morbidity, psychological trauma and expense associated with prematurity. There should be more focus on biochemical marker as predictor of preterm birth to establish their clinical utility.

More studies are needed for understanding of mechanism of preterm birth, that would help in tailoring the management strategies for early prediction and prevention of preterm birth.

Identification and primary prevention of modifiable risk factors would help in reducing the prevalence of preterm birth.

Cervicovaginal hCG can be used as biochemical predictor of preterm birth in asymptomatic high-risk women.

\section{ACKNOWLEDGMENTS}

Authors would like to thank to guide and mentor Dr Manas Kabiraj and to all teachers, hospital staff, friends and family member.
Funding: No funding sources

Conflict of interest: None declared

Ethical approval: The study was approved by the Institutional Ethics Committee

\section{REFERENCES}

1. World Health Organization. Media Centre. Preterm Birth. Factsheet updated November 2015. Available at: http://www. who.int/mediacentre/factsheets/fs363/en/. Accessed on $24^{\text {th }}$ March 2020 .

2. Singh B, Goswami B, Gupta N, Bajaj A, Mallika, V. Identification of biomarkers for prediction of preterm delivery. J Med Society. 2011;26(1):41-5.

3. Offiah I, O’Donoghue K, Kenny L. Clinical risk factors for preterm birth. Preterm Birth-Mother and Child. 1st ed. InTech; 2012:73-94.

4. Goldenberg R, Culhane J, Romero R. Epidemiology and causes of preterm birth. Lancet. 2008;371(9606):75-84

5. Alijahan, R, Hazrati, S, Mirzarahimi, M, Pourfarzi, F, Hadi, P. Prevalence and risk factors associated with preterm birth in Ardabil, Iran. Iran J Reprod Med. 2014;12(1):47-56.

6. Tellapragada C, Eshwara VK, Bhat P, Acharya S, Kamath A, Bhat S, et al. Risk factors for preterm birth and low birth weight among pregnant indian women: a hospital-based prospective study. J Prev Med Public Health. 2016;49(3):165-75.

7. Nguyen N, Savitz DA, Thorp JM. Risk factors for preterm birth in Vietnam. Int J Gynaecol Obstet. 2004;86(1):70-8.

8. Di Renzo GC, Giardina I, Rosati A, Clerici G, Torricelli M, Petraglia F. Italian preterm network study group. Maternal risk factors for preterm birth: a country-based population analysis. Eur J Obstet Gynecol Reprod Biol. 2011;159(2):342-6.

9. Sak ME, Sak S, Gul T. Beta-human chorionic gonadotropin concentrations in cervicovaginal secretions as an early marker of preterm delivery. J Clin Exp Invest. 2010;1(1):16-20.

10. Shah J, Baxi B. Identification of biomarkers for prediction of preterm delivery. J Med Society. 2016;30(1):3.

11. Alakananda D, Hazarika D. Human $\beta-h C G$ in cervicovaginal secretions as a predictor of preterm delivery. J Dent Medi Sci. 2016;15(10):1-3.

12. Heine RP, McGregor JA, Goodwin TM, Artal R, Hayashi RH, Robertson PA, et al. Serial salivary estriol to detect an increased risk of preterm birth. Obstet Gynecol. 2000;96(4):490-7.

13. Soghra K, Zohreh S, Kobra AK, Reza MM. Single measurement of salivary estriol as a predictor of preterm birth. Pak J Biol Sci. 2014;17(5):730-4.

14. Hadzi Lega M, Daneva Markova A, Stefanovic M, Tanturovski M. Interleukin 6 and fetal fibronectin as a predictor of preterm delivery in symptomatic patients. Bos J Basic Med Sci. 2015;15(1):51. 
15. Kim A, Lee E, Shin J, Kim H. Identification of biomarkers for preterm delivery in mid-trimester amniotic fluid. Placenta. 2013;34(10):873-8.

16. Elkhadary A, Temamy E, Hasanen E, Elhelw E, Eldin A, Serour A, et al. The correlation between fetal fibronectin, bacterial vaginosis and cervical length in prediction of preterm labour. J Pregnancy Child Health. 2017;4(2):1-7.

17. Magro-Malosso E, Seravalli V, Cozzolino $M$, Spitaleri M, Susini T, Di Tommaso M. Prediction of preterm delivery by fetal fibronectin in symptomatic and asymptomatic women with cervical length $\leq 20 \mathrm{~mm}$. The J Maternal-Fetal Neo Med. 2016;30(3):294-97.

18. Skoll A, St. Louis P, Amiri N, Delisle M, Lalji S. The evaluation of the fetal fibronectin test for prediction of preterm delivery in symptomatic patients. J Obstet Gynaecol Canada. 2006;28(3):20613.

19. Shahshahan Z, Iravani H. Comparison of CRP and ALK-P serum levels in prediction of preterm delivery. Adv Biomed Res. 2016;5(1):17.

20. Meyer R, Thompson S, Addy C, Garrison C, Best R. Maternal serum placental alkaline phosphatase level and risk for preterm delivery. Am J Obstet Gynecol. 1995;173(1):181-6.

21. Guvenal T, Kantas E, Erselcan T, Culhaoglu Y, Cetin A. Beta-human chorionic gonadotropin and prolactin assays in cervicovaginal secretions as a predictor of preterm delivery. Int J Gynaecol Obstet. 2001;75(3):229-34.

22. Leylek O, Songur S, Erselcan T, Cetin A, Izgic E. Cervicovaginal washing prolactin assay in prediction of preterm delivery. Int $\mathbf{J}$ Gynecol Obstet. 1997;59(1):7-12.

23. Kalantaridou SN, Zoumakis E, Makrigiannakis A, Lavasidis LG, Vrekoussis T, Chrousos GP. Corticotropin-releasing hormone, stress and human reproduction: an update. $\mathbf{J}$ Reprod Immunol. 2010;85(1):33-9.

24. Makrigiannakis A, Semmler M, Briese V, Eckerle H, Minas V, Mylonas I, et al. Maternal serum corticotropin-releasing hormone and ACTH levels as Predictive markers of premature labor. Int $\mathbf{J}$ Gynaecol Obstet. 2007;97(2):115-9.

25. O'Hara S, Zelesco M, Sun Z. Cervical length for predicting preterm birth and a comparison of ultrasonic measurement techniques. Austral J Ultrasound Med. 2013;16(3):124-34.

26. Lim K, Butt K, Crane JM. Diagnostic imaging committee; family physicians advisory committee; maternal fetal medicine committee. SOGC clinical practice guideline. Ultrasonographic cervical length assessment in predicting preterm birth in singleton pregnancies. J Obstet Gynaecol Can. 2011;33(5):486-99.

27. Di Tommaso M, Berghella V. Cervical length for the prediction and prevention of preterm birth. Exp Rev Obstet Gynecol. 2013:8(4):345-55.

28. Iams JD, Goldenberg RL, Meis PJ, Mercer BM, Moawad A, Das A, et al. The length of the cervix and the risk of spontaneous premature delivery. National institute of child health and human development maternal fetal medicine unit network. $\mathrm{N}$ Engl J Med. 1996;334(9):567-72.

29. Anai T, Tanaka Y, Hirota Y, Miyakawa I. Vaginal fluid hCG levels for detecting premature rupture of membranes. Obstet Gynecol. 1997;89(2):261-4.

30. Tellapragada C, Eshwara VK, Bhat P, Acharya S, Kamath A, Bhat S, et al. Risk factors for preterm birth and low birth weight among pregnant Indian women: a hospital-based prospective study. J Prev Med Public Health. 2016;49(3):165-75.

31. Bernstein PS, Stern R, Lin N, Furgiuele J, Karmen A, Comerford-Freda M, et al. Beta-human chorionic gonadotropin in cervicovaginal secretions as a predictor of preterm delivery. Am J Obstet Gynecol. 1998;179(4):870-3.

32. Garshasbi A, Ghazanfari T, Faghih Zadeh S. Betahuman chorionic gonadotropin in cervicovaginal secretions and preterm delivery. Int $\mathbf{J}$ Gynecol Obstet. 2004;86(3):358-64.

33. Abasalizadeh $\mathrm{S}$, Abasalizadeh F, Sahaf F. Cervicovaginal beta HCG test in prediction of spontaneous preterm delivery among normal pregnant women. research J Biol Sci. 2007;2(6):6303 .

34. Adhikari K, Bagga R, Suri V, Arora S, Masih S. Cervicovaginal HCG and cervical length for prediction of preterm delivery in asymptomatic women at high risk for preterm delivery. Arch Gynecol Obstet. 2009;280(4):565-72.

35. Mishra N, Kausar U. Assessment of cervicovaginal HCG and cervical length in prediction of labour. New Indian J Obgyn. 2017;4(1):71-6.

Cite this article as: Gupta R, Mukherjee P, Kaur H, Singhal S. Role of cervicovaginal $\beta$-hCG in prediction of preterm delivery: a prospective observational study. Int J Reprod Contracept Obstet Gynecol 2020;9:3677-82. 